\title{
The Regulation of Hydrogen and Oxygen Escape from Mars
}

\author{
S. C. LIU and T. M. DONAHUE \\ Space Physics Research Laboratory, Department of Atmospheric and Oceanic Science, \\ University of Michigan, Ann Arbor, Michigan 48105
}

Received May 1, 1975 ; Rovised June 24, 1975

\begin{abstract}
It is shown that under present conditions the Jeans escape flux of hydrogen from Mars in the form of $\mathrm{H}$ and $\mathrm{H}_{2}$ is constrained to be the same as twice the non. thermal (McElroy, 1972) escape of $\mathrm{O}$ atoms. The mediation of the chemical chain that recombines $\mathrm{CO}_{2}$ plays an essential role in regulating the escape of hydrogen to match that of oxygen, confirming a mechanism postulated by McElroy and Donahue (1972). It is also shown that if the oxygen flux changes, a change in the $\mathrm{O}_{2}$ mixing ratio results and the consequence is to induce a large change in the odd hydrogen concentration, and consequently in $\mathrm{H}_{2}$ production and hydrogen escape. The effect is to stabilize the hydrogen escape flux at twice the $O$ flux. It is shown that surface chemistry should not change the operation of this mechanism but has consequences for the eddy coefficient variation at low altitudes. There is a strong correlation between low humidity, large solar zenith angles and large $\mathrm{O}_{3}$ abundances. The effect of argon in a mixing ratio as large as 0.3 on these results is also investigated.
\end{abstract}

\section{INTRODUCTION}

One of the fundamental problems of atmospheric chemistry is that of understanding the stability of $\mathrm{CO}_{2}$ in the atmospheres of Mars and Venus. There are problems in understanding the low degree of dissociation in the low as well as in the upper atmospheres of each planet. They stem from the fact that, whereas $\mathrm{CO}_{2}$ undergoes photolysis at a global mean rate of $3 \times 10^{12} \mathrm{~cm}^{-2} \mathrm{sec}^{-1}$ (in the atmosphere of Mars) and only very slowly recombines from $\mathrm{CO}$ and $\mathrm{O}\left({ }^{3} \mathrm{P}\right)$, the concentrations of $\mathrm{CO}$ and atomic oxygen are very low in the upper atmosphere and the mixing ratios of $\mathrm{CO}$ and $\mathrm{O}_{2}$ are also low for the atmosphere as a whole, attaining a value of only about $10^{-3} \mathrm{v} / \mathrm{v}$. Yet the three-body rate constant for recombination of $\mathrm{O}$ with $\mathrm{CO}$ is very small, $2 \times 10^{-37} \mathrm{~cm}^{6} \mathrm{sec}^{-1}$, compared to that for formation of $\mathrm{O}_{2}$ from two oxygen atoms under equivalent conditions, $7 \times 10^{-33} \mathrm{~cm}^{6} \mathrm{sec}^{-1}$. The amount of atomic oxygen in the upper atmosphere can be created by photolysis of $\mathrm{CO}_{2}$ in about $1.5 \times 10^{3} \mathrm{sec}$. It has been shown that there is only one viable solution to the problem of maintaining the ratio of atomic oxygen to $\mathrm{CO}_{2}$ near $135 \mathrm{~km}$ at a value between $5 \times 10^{-3}$ and $10^{-2}$ (Strickland et al., 1972). It is necessary to remove the oxygen at an effective downward velocity of 500 to $100 \mathrm{~cm} / \mathrm{sec}$ (Donahue, 1971 ; McElroy and McConnell, 1971). This is equivalent to an eddy diffusion coefficient between 5 and $10 \times 10^{8} \mathrm{~cm}^{2} \mathrm{sec}^{-1}$ above $100 \mathrm{~km}$ if the transport is considered to occur because of eddy diffusion.

But in the lower atmosphere $\mathrm{O}_{2}$ apparently should form in great amounts even if the oxygen is rapidly removed from the upper atmosphere. The observed amount is $1.3 \times 10^{-3}$ times the $\mathrm{CO}_{2}$ abundance (Barker, 1972; Carleton and Traub, 1972) and the photolysis rate is $5 \times 10^{10} \mathrm{~cm}^{-2}$ $\sec ^{-1}$. This gives every $\mathrm{O}_{2}$ molecule a very long lifetime, about $10^{10} \mathrm{sec}$ against this form of destruction. In view of the large three-body formation rate it is necessary to find a way, other than photolysis, to break $\mathrm{O}_{2}$ bonds at a rapid rate, to keep the production rate of $\mathrm{O}_{2}$ to a very low value, or to find a mechanism that combines some measure of both of these properties.

The literature already contains excellent 
reviews of some of the material in this introduction (McConnell, 1973; Hunten, 1974 ; McElroy, 1974). Since this paper is a contribution to a symposium, it will repeat parts of these reviews. A model that depends predominantly on the solution involving breaking the $\mathrm{O}_{2}$ bonds was proposed by Parkinson and Hunten (1972), and it is discussed later in this paper. A solution that essentially short-circuits $\mathrm{O}_{2}$ formation was favored in a model proposed by McElroy and Donahue (1972). This second solution features a scheme for recombination of $\mathrm{O}$ and $\mathrm{CO}$ rather than $O$ and $O$ and involves bringing atmic oxygen down to the neighborhood of $30 \mathrm{~km}$ so rapidly that it has almost no chance of recombining by forming $\mathrm{O}_{2}$ before the radical $\mathrm{HO}_{2}$ begins to be produced in a three-body reaction at a rapid rate. This enables a catalytic cycle to operate efficiently:

$$
\begin{array}{ll}
\mathrm{H}+\mathrm{O}_{2}+\mathrm{M} \rightarrow \mathrm{HO}_{2}+\mathrm{M}, & \mathrm{R} 17, \\
\mathrm{HO}_{2}+\mathrm{O} \rightarrow \mathrm{OH}+\mathrm{O}_{2}, & \mathrm{R3}, \\
\mathrm{CO}+\mathrm{OH} \rightarrow \mathrm{CO}_{2}+\mathrm{H}, & \mathrm{R} 16, \\
\quad \mathrm{Net}=\mathrm{CO}+\mathrm{O} \rightarrow \mathrm{CO}_{2} . &
\end{array}
$$

The hydrogen atoms are supplied by dissociation of $\mathrm{H}_{2} \mathrm{O}$. The eddy diffusion coefficient required to produce such effective transport has to be greater than $1.5 \times 10^{8}$ $\mathrm{cm}^{2} \mathrm{sec}^{-1}$ at all altitudes above $30 \mathrm{~km}$.

Almost all of the $\mathrm{O}_{2}$ in the system is formed by the reaction

$$
\mathrm{O}+\mathrm{OH} \rightarrow \mathrm{O}_{2}+\mathrm{H}, \quad \mathrm{R2},
$$

between 25 and $30 \mathrm{~km}$. Photolysis of $\mathrm{O}_{2}$ in the Herzberg continuum, occurring mostly between 2 and $15 \mathrm{~km}$, is the major sink for $\mathrm{O}_{2}$ although some destruction results from photolysis of $\mathrm{H}_{2} \mathrm{O}_{2}$ after its formation from $\mathrm{HO}_{2}$ below $10 \mathrm{~km}$. Several conditions are imposed on the system. The principal one is that the integrated rates of reactions (1) to (3) be equal to the integrated rate of production of $\mathrm{O}$ atoms by photolysis of $\mathrm{CO}_{2}$ and to each other. Subsidiary conditions are that the production of $\mathrm{H}_{2}$ from branch (a) of the reaction

$$
\begin{aligned}
\mathrm{H}+\mathrm{HO}_{2} \rightarrow & \mathrm{H}_{2}+\mathrm{O}_{2}, \quad \mathrm{R5}, \quad \text { (a) } \\
& \mathrm{OH}+\mathrm{OH}, \\
& \mathrm{H}_{2} \mathrm{O}+\mathrm{O},
\end{aligned}
$$

be half the thermal (Jeans) escape flux of $\mathrm{H}$ atoms and that the formation of $\mathrm{H}_{2} \mathrm{O}$ from the reaction

$$
\mathrm{OH}+\mathrm{HO}_{2} \rightarrow \mathrm{H}_{2} \mathrm{O}+\mathrm{O}_{2}, \quad \mathrm{R7},
$$

equal the rate of photolysis of $15 \mu \mathrm{m}$ of precipitable water $\left(5 \times 10^{19}\right.$ molecules $\mathrm{cm}^{-2}$ ) (Schorn, 1971 ; Barker et al., 1970; Conrath et al., 1973). This is to say that water is made at a rate of about $2 \times 10^{9}$ molecules $\mathrm{cm}^{-2} \mathrm{sec}^{-1}$. The $\mathrm{O}_{3}$ abundance is $1.4 \mu \mathrm{m}-a t m$ in the model and this is well below the limit of $3 \mu \mathrm{m}$-atm set by $u v$ spectroscopy (Barth et al., 1973; Barth and Dick, 1974) in regions where the amount of water vapor lies in the range $10-20 \mu \mathrm{m}$ of precipitable water. The ozone in this model is also concentrated close to the surface. Since it is the odd hydrogen resulting from water vapor dissociation that suppresses the odd oxygen in this model, it is not qualitatively surprising that as much as 10 to $60 \mu \mathrm{m}$-atm of $\mathrm{O}_{3}$ were detected by Mariner 9 (Barth and Dick, 1974) above the polar caps where there is less than $1 \mu \mathrm{m}$ of precipitable water.

The photochemical scheme proposed seems to offer a natural explanation for the discovery by McElroy (1972) that atomic oxygen escapes from Mars at the rate of about $7 \times 10^{7}$ atoms $\mathrm{cm}^{-2} \mathrm{sec}^{-1}$, or about half the thermal escape rate of hydrogen and consequently that there is no accumulation of oxygen on the planet. An $\mathrm{H}$ escape flux of $1.8 \times 10^{8} \mathrm{~cm}^{-2} \mathrm{sec}^{-1}$ would leave behind $2.4 \times 10^{20}$ molecules $\mathrm{cm}^{-2}$ in $10^{5} \mathrm{yr}$. This is the amount now found in the atmosphere. Thus there is another problem of accounting for the lack of oxygen on the planet, that of disposing of the $\mathrm{O}_{2}$ belonging to the $\mathrm{H}_{2} \mathrm{O}$ which has lost its hydrogen. McElroy's nonthermal escape mechanism for atomic oxygen is based on the recognition that dissociative recombination of $\mathrm{CO}_{2}{ }^{+}$and $\mathrm{O}_{2}{ }^{+}$with electrons produces oxygen atoms in both cases, whether the products of dissociation are electronically excited or not, with greater than their escape energy of $1.99 \mathrm{eV}$. Hence about half of the ions created above the exobase will produce oxygen atoms traveling upward with greater than escape velocity. McElroy and Donahue (1972) argued that the balance 
between the hydrogen escape flux and the oxygen escape flux was probably not an accident. They reasoned that in their chemical scheme the rate of oxygen escape determined the rate of hydrogen escape by determining the magnitude of the integral

$$
I_{1}=\int k_{s}[\mathrm{H}]\left[\mathrm{HO}_{2}\right] d z,
$$

where the bracket denotes as usual the density of the species enclosed. This integral gives the rate at which $\mathrm{H}_{2}$ molecules are formed. These then flow upward to supply the escaping hydrogen atoms. A decrease in atomic oxygen escape flux would lead to an increase in $\mathrm{CO}$ and $\mathrm{O}_{2}$ concentration and hence a decrease in odd hydrogen. This follows because the integrals

and

$$
\begin{aligned}
I_{2} & =\int k_{16}[\mathrm{CO}][\mathrm{OH}] d z \\
& =\int k_{17}[\mathrm{H}]\left[\mathrm{O}_{2}\right][\mathrm{M}] d z
\end{aligned}
$$

$$
I_{3}=\int k_{7}[\mathrm{OH}]\left[\mathrm{HO}_{2}\right] d z
$$

that determine the rate of $\mathrm{CO}_{2}$ and $\mathrm{H}_{2} \mathrm{O}$ recombination are constrained to remain invariant.

However, in the calculations of McElroy and Donahue (1972) it was not verified that the detailed solution of the coupled flow equations from the surface to the base of the exosphere produced the observed escape flux of hydrogen. Nor was it demonstrated that changing the oxygen escape flux would indeed provoke a change in hydrogen escape in such a way as to drive the system to a new stable state in which oxygen and twice hydrogen escape fluxes would again be equal. That thesis is not self-evident, particularly in view of the recent work of Hunten (1973), Hunten and Strobel (1974), and Liu and Donahue $(1974 a, 1974 b, 1974 c)$ showing that the escape flux of hydrogen on Earth is determined by the mixing ratio of hydrogen compounds in the stratosphere and very little influenced by factors such as the rates of transport, chemical or dissociative processes in the mesosphere and lower thermosphere. This is the case when the temperature is sufficiently high in the exosphere to establish limiting flux conditions. Thus one might expect the mixing ratio of water in the stratosphere to control the escape rate of hydrogen on Mars since the mixing ratio of $\mathrm{H}_{2} \mathrm{O}$ is assumed to remain constant. However, it will appear in the course of this paper that limiting flux in fact does not occur on Mars, that the oxygen flux is in fact equal to half the hydrogen flux as calculated in the model under present Martian conditions, and that the oxygen flux does indeed control the hydrogen flux. The validity of the last statement will be demonstrated by assuming that, while the atmosphere remains unchanged in its $\mathrm{CO}_{2}$ and $\mathrm{H}_{2} \mathrm{O}$ contents and in the vertical profiles of temperature and eddy coefficient, the $\mathrm{O}_{2}$ abundance is different from its present value. It will be shown that under such circumstances the quasi-steady state calls for a change in $\mathrm{H}$ and $\mathrm{H}_{2}$ densities at the base of exosphere considerably greater in magnitude and opposite in sense to the change in the amount of $\mathrm{O}_{2}$ in the atmosphere. Then the effective escape rate of $\mathrm{H}_{2}$ and $\mathrm{O}$ would be unbalanced. This would not represent a true steady state, however, because $\mathrm{H}_{2}$ and thus the escaping hydrogen is produced by branch (a) of R5 involving $\mathrm{O}_{2}$. Thus, for example, suppose that the nonthermal escape flux of atomic oxygen for some reason, such as enhanced solar euv flux were to double. The $\mathrm{O}_{2}$ mixing ratio would then begin to decrease, approaching a value half the present one. But the hydrogen escape flux would increase even faster and attain a value equal to twice the $O$ flux before $\mathrm{O}_{2}$ could reach half its present concentration. The escape of water would then be stabilized at a new value. The hydrogen escape flux could not continue to increase because, since its source is R5a, it must be in balance with the production of $\mathrm{HO}_{2}$. Enhanced production of $\mathrm{HO}_{2}$ would not be possible if the $\mathrm{O}_{2}$ concentration were to continue to decrease. Thus the new steady state would be one in which the escape of water is double the present rate, but the $\mathrm{O}_{2}$ concentration more than half its present value.

\section{Hydrogen Escape Flux}

Our technique is the one described in our papers on hydrogen chemistry and 
escape for Earth and Venus (Liu and Donahue, 1974a, 1974b, 1974c, 1975). A standard $\mathrm{CO}_{2}$ model atmosphere with an exosopheric temperature of $320 \mathrm{~K}$ is assumed (NASA, 1974). The $\mathrm{O}_{2}$ and precipitable $\mathrm{H}_{2} \mathrm{O}$ abundances are fixed at $1.3 \times 10^{-3}\left[\mathrm{CO}_{2}\right]$ and $15 \mu \mathrm{m}$. The density of atomic hydrogen at the exobase, $226 \mathrm{~km}$, is fixed at $3 \times 10^{4} \mathrm{~cm}^{-3}$ (Anderson, 1973) so that the thermal escape flux of atomic hydrogen is predetermined. Coupled diffusion equations involving eddy and Fickian diffusion are solved for the densities of $\mathrm{CO}, \mathrm{O}_{2}, \mathrm{H}_{2}, \mathrm{H}_{2} \mathrm{O}, \mathrm{H}_{2} \mathrm{O}_{2}, \mathrm{HO}_{\mathrm{x}}$, and

TABLE I

\begin{tabular}{|c|c|c|c|}
\hline $\begin{array}{l}\text { Reaction } \\
\text { number }\end{array}$ & Reaction & Rate constant & Reference \\
\hline Rl & $\mathrm{H}+\mathrm{O}_{3} \rightarrow \mathrm{OH}+\mathrm{O}_{2}$ & $k_{1}=2.6 \times 10^{-11}$ & a \\
\hline $\mathrm{R} 2$ & $\mathrm{OH}+\mathrm{O} \rightarrow \mathrm{H}+\mathrm{O}_{2}$ & $k_{2}=5 \times 10^{-11}$ & $b$ \\
\hline R3 & $\mathrm{HO}_{2}+\mathrm{O} \rightarrow \mathrm{OH}+\mathrm{O}_{2}$ & $k_{3}=5 \times 10^{-11}$ & $c, d$ \\
\hline R4 & $\mathrm{H}+\mathrm{HO}_{2} \rightarrow \mathrm{OH}+\mathrm{OH}$ & $k_{4}=10^{-10} \exp (-330 / T)$ & $e$ \\
\hline R5 & $\mathrm{H}+\mathrm{HO}_{2} \rightarrow \mathrm{H}_{2}+\mathrm{O}_{2}$ & $k_{5}=3 \times 10^{-11} \exp (-330 / T)$ & e \\
\hline R6 & $\mathrm{OH}+\mathrm{OH} \rightarrow \mathrm{H}_{2} \mathrm{O}+\mathrm{O}$ & $k_{6}=2 \times 10^{-12}$ & c \\
\hline R7 & $\mathrm{OH}+\mathrm{HO}_{2} \rightarrow \mathrm{H}_{2} \mathrm{O}+\mathrm{O}_{2}$ & $k_{7}=2 \times 10^{-10}$ & 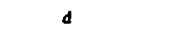 \\
\hline $\mathrm{R} 8$ & $\mathrm{OH}+\mathrm{H}_{2} \rightarrow \mathrm{H}_{2} \mathrm{O}+\mathrm{H}$ & $k_{\mathrm{B}}=3.8 \times 10^{-11} \exp (-2600 / T)$ & 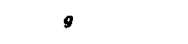 \\
\hline R9 & $\mathrm{O}+\mathrm{H}_{2} \rightarrow \mathrm{OH}+\mathrm{H}$ & $k_{9}=7 \times 10^{-11} \exp (-5000 / T)$ & c \\
\hline RIO & $\mathrm{HO}_{2}+\mathrm{HO}_{2} \rightarrow \mathrm{H}_{2} \mathrm{O}_{2}+\mathrm{O}_{2}$ & $k_{10}=3 \times 10^{-11} \exp (-500 / T)$ & $h$ \\
\hline R11 & $\mathrm{OH}+\mathrm{H}_{2} \mathrm{O}_{2} \rightarrow \mathrm{HO}_{2}+\mathrm{H}_{2} \mathrm{O}$ & $k_{11}=4.1 \times 10^{-11} T^{1 / 2} \exp (-600 / T)$ & 1 \\
\hline R12a & $\mathrm{H}_{2} \mathrm{O}_{2}+\mathrm{O} \rightarrow \mathrm{H}_{2} \mathrm{O}+\mathrm{O}_{2}$ & $k_{12 a}=2.3 \times 10^{-11} \exp (-3200 / T)$ & $J$ \\
\hline $\mathrm{R} I 2 \mathrm{~b}$ & $\mathrm{H}_{2} \mathrm{O}_{2}+\mathrm{O} \rightarrow \mathrm{OH}+\mathrm{HO}_{2}$ & $k_{12 b}=2.3 \times 10^{-11} \exp (-3200 / T)$ & $J$ \\
\hline RI3 & $\mathrm{O}\left({ }^{1} \mathrm{D}\right)+\mathrm{H}_{2} \mathrm{O} \rightarrow 2 \mathrm{OH}$ & $k_{13}=3 \times 10^{-10}$ & k \\
\hline Rl4 & $\mathrm{O}\left({ }^{1} \mathrm{D}\right)+\mathrm{H}_{2} \rightarrow \mathrm{OH}+\mathrm{H}$ & $k_{14}=3 \times 10^{-10}$ & 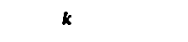 \\
\hline $\mathrm{R} 15$ & $\mathrm{O}\left({ }^{1} \mathrm{D}\right)+\mathrm{CO}_{2} \rightarrow \mathrm{O}+\mathrm{CO}_{2}$ & $k_{15}=1.8 \times 10^{-10}$ & 1 \\
\hline R16 & $\mathrm{CO}+\mathrm{OH} \rightarrow \mathrm{H}+\mathrm{CO}_{2}$ & $k_{16}=9 \times 10^{-13} \exp (-500 / T)$ & c \\
\hline Rl7 & $\mathrm{H}+\mathrm{O}_{2}+\mathrm{CO}_{2} \rightarrow \mathrm{HO}_{2}+\mathrm{CO}_{2}$ & $k_{17}=2 \times 10^{-13}(T / 273)^{-1.3}$ & $n$ \\
\hline $\mathrm{R} 18$ & $\mathrm{CO}+\mathrm{O}+\mathrm{CO}_{2} \rightarrow \mathrm{CO}_{2}+\mathrm{CO}_{2}$ & $k_{18}=2 \times 10^{-37}$ & $0, p, Q$ \\
\hline $\mathrm{R} 19$ & $\mathrm{O}+\mathrm{O}+\mathrm{CO}_{2} \rightarrow \mathrm{O}_{2}+\mathrm{CO}_{2}$ & $k_{19}=3 \times 10^{-33}(T / 300)^{-2.9}$ & c \\
\hline $\mathbf{R} 20$ & $\mathrm{O}+\mathrm{O}_{2}+\mathrm{CO}_{2} \rightarrow \mathrm{O}_{3}+\mathrm{CO}_{2}$ & $k_{20}=1.4 \times 10^{-33}(T / 300)^{-2.5}$ & c \\
\hline R21 & $\mathrm{CO}_{2}^{+}+\mathrm{H}_{2} \rightarrow \mathrm{CO}_{2} \mathrm{H}^{+}+\mathrm{H}$ & $k_{21}=1.4 \times 10^{-9}$ & r \\
\hline $\mathrm{R} 22$ & $\mathrm{CO}_{2} \mathrm{H}^{+}+\mathrm{O} \rightarrow \mathrm{CO}_{2}+\mathrm{H}$ & $k_{22}=3.5 \times 10^{-7}$ & Assumed \\
\hline R23 & $\mathrm{O}^{+}+\mathrm{CO}_{2} \rightarrow \mathrm{O}_{2}^{+}+\mathrm{CO}$ & $k_{23}=1.2 \times 10^{-9}$ & $r$ \\
\hline $\mathbf{R 2 4}$ & $\mathrm{O}^{+}+\mathrm{H}_{2} \rightarrow \mathrm{OH}^{+}+\mathrm{H}$ & $k_{24}=2.0 \times 10^{-9}$ & $r$ \\
\hline R25 & $\mathrm{H}^{+}+\mathrm{O}^{+} \rightarrow \mathrm{O}^{+}+\mathrm{H}$ & $k_{25}=3.8 \times 10^{-10}$ & $s$ \\
\hline R26 & $\mathrm{O}^{+}+\mathrm{H} \rightarrow \mathbf{H}^{+}+\mathrm{O}$ & $k_{26}=6.8 \times 10^{-10}$ & s \\
\hline R27 & $\mathrm{O}_{2}^{+}+\mathrm{e} \rightarrow \mathrm{O}+\mathrm{O}$ & $k_{27}=8.75 \times 10^{-6}(\mathrm{Te})^{-0.67}$ & $t$ \\
\hline R28 & $\mathrm{CO}_{2}^{+}+\mathrm{\theta} \rightarrow \mathrm{CO}+\mathrm{O}$ & $k_{28}=1.14 \times 10^{-4}(T e)^{-1}$ & * \\
\hline R29 & $\mathrm{OH}^{+}+\mathrm{e} \rightarrow \mathrm{H}+\mathrm{O}$ & $k_{29}=2.2 \times 10^{-7}$ & Assumed \\
\hline R30 & $\mathrm{CO}_{2}^{+}+\mathrm{O} \rightarrow \mathrm{O}_{2}^{+}+\mathrm{CO}$ & $k_{30}=1.6 \times 10^{-10}$ & $\cdot$ \\
\hline R31 & $\mathrm{CO}_{2}^{+}+\mathrm{O} \rightarrow \mathrm{O}^{+}+\mathrm{CO}_{2}$ & $k_{31}=9.6 \times 10^{-11}$ & 0 \\
\hline \multirow{10}{*}{\multicolumn{2}{|c|}{$\begin{array}{l}\text { ' Phillips and Schiff (1962). } \\
\text { 'Clyne and Thrush (1963a). } \\
\text { ' Kaufman (1964, 1969a, 1969b). } \\
\text { ' Hochanadel et al. (1972). } \\
\text { ' Schofield (1967). } \\
\text { ' Wilson (1972). } \\
\text { "Hampson et al. (1973). } \\
\text { 'Greiner (1968). } \\
\text { J Albers et al. (1971). } \\
\text { * Biedenkapp et al. (1970). }\end{array}$}} & 'Clark and Noxon (1972). & \\
\hline & & "Baulch et al. (1969). & \\
\hline & & - Simonaitis and Heicklen (1972). & \\
\hline & & Stuhl and Niki (1871). & \\
\hline & & Slanger et al. (1872). & \\
\hline & & r Fehsenfeld et al. (1869) & \\
\hline & & ${ }^{3}$ Fehsenfeld and Ferguson (1872). & \\
\hline & & ${ }^{t}$ Walls and Dunn (1974). & \\
\hline & & " Bauer (1973). & \\
\hline & & - Fehsenfeld et al. (1970). & \\
\hline
\end{tabular}


$\mathrm{O}_{\mathrm{x}}$ from the surface of Mars to its exobase. Odd hydrogen $\mathrm{HO}_{\mathrm{x}}$ comprises the rapidly interconverting species $\mathrm{H}, \mathrm{OH}$ and $\mathrm{HO}_{2}$ while $\mathrm{O}_{x}$ comprises $\mathrm{O}, \mathrm{O}_{3}, \mathrm{OH}$ and $\mathrm{HO}_{2}$. Every species is required to satisfy the standard diffusion equation, the continuity equation, and

$$
\begin{aligned}
\int_{0}^{226 \mathrm{~km}}\left[p_{i}(z)-l_{i}(z)\right] d z= & \phi_{l}(226 \mathrm{~km}) \\
& -\phi_{l}(0 \mathrm{~km}),
\end{aligned}
$$

where $\phi_{i}, p_{i}$, and $l_{i}$ are local flux, production rates and loss rates for the $i$ th atmospheric species. Except for $\mathrm{H}_{2} \mathrm{O}$ we assume no flux at the surface. The $\mathrm{H}_{2} \mathrm{O}$ outgassing rate is taken to be equal to one-half the hydrogen escape flux. It is also required that the mixing ratio of $\mathrm{CO}$ in an acceptable solution fall within the observed range $7 \times 10^{-4}$ to $3.2 \times 10^{-3}$ (Carleton and Traub, 1972 ; Young, 1971). The mixing ratio of
$\mathrm{CO}$ is otherwise allowed to vary, as is the eddy diffusion coefficient, until we obtain a solution satisfying the constraints. In arriving at our model we calculate ion density profiles, varying the solar ionizing flux to obtain agreement with Mariner 9 election density profiles. The ionospheric model is important, of course, in determining the rate of oxygen escape and the rate of conversion of $\mathrm{H}_{2}$ to $\mathrm{H}$. In Table $\mathrm{I}$ we present the chemical, ion-molecule, ionelectron and photolysis rate constants used in our model calculations.

It is immediately apparent that assuming the water vapor concentration to be determined by mixing and photochemical processes alone from the surface upward produces serious problems. The difficulty is that when there is sufficient $\mathrm{H}_{2} \mathrm{O}$ to supply by photolysis the hydrogen atoms that rise to the exobase, photolysis occurs in the

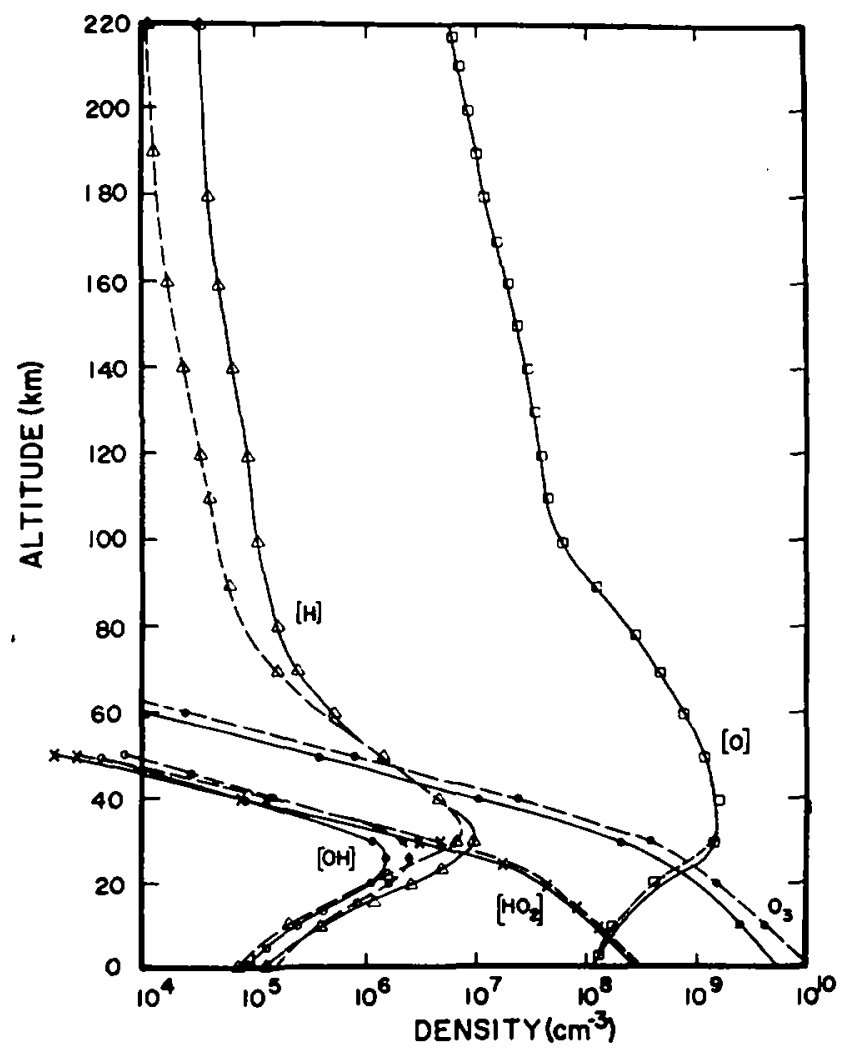

FIa. 1. Density distributions of $\mathrm{H}, \mathrm{OH}, \mathrm{HO}_{2}, \mathrm{O}$, and $\mathrm{O}_{3}$ for two values of the $\mathrm{O}_{2}$ mixing ratio: $1.3 \times 10^{-3}$ and $2.6 \times 10^{-3}$. Solid lines correspond to $1.3 \times 10^{-3} \mathrm{O}_{2}$ mixing ratio and dashed lines correspond to $2.6 \times 10^{-3} \mathrm{O}_{2}$ mixing ratio. 
neighborhood of 30 to $40 \mathrm{~km}$ and the $\mathrm{OH}$ density is so high that the production of $\mathrm{O}_{2}$ by the reaction $\mathbf{R 2}(4)$ is prohibitively large. Therefore, it is necessary to assume instead (a reasonable assumption after all) that $\mathrm{H}_{2} \mathrm{O}$ follows a saturation profile from the surface to $15 \mathrm{~km}$ (Hunten and McElroy, 1970). The scale height of this distribution is so small that virtually all the precipitable $\mathrm{H}_{2} \mathrm{O}$ is contained below $10 \mathrm{~km}$. The $\mathrm{H}_{2} \mathrm{O}$ density at the surface is $6 \times 10^{14} \mathrm{~cm}^{-3}$, while that at $10 \mathrm{~km}$ is fixed at $2 \times 10^{9} \mathrm{~cm}^{-3}$. Above $15 \mathrm{~km}$ the $\mathrm{H}_{2} \mathrm{O}$ is assumed to obey the coupled flow equations. The great advantage of this assumption is the $\mathrm{H}_{2} \mathrm{O}$ supplies the odd hydrogen precisely where it is needed for the recombination cycle (near the surface) by reaction $\mathrm{R} 13$ of $\mathrm{H}_{2} \mathrm{O}$ with $O\left({ }^{1} \mathrm{D}\right)$, where the latter species is produced in turn from $\mathrm{O}_{3}$ photolysis. The odd hydrogen also provides a large source of $\mathrm{H}_{2}$ at low altitudes (near $25 \mathrm{~km}$ ) through the reaction branch (5a).
If we assume that the rate constant for this branch of the $\mathrm{H}, \mathrm{HO}_{2}$ reaction is $3 \times 10^{-11} \exp (-330 / T)$, as McElroy and Donahue (1972) did, then the $\mathrm{H}_{2}$ is virtually the sole source of escaping hydrogen atoms, and it supplies them in the ionospheric reactions

$$
\begin{array}{ll}
\mathrm{CO}_{2}{ }^{+}+\mathrm{H}_{2} \rightarrow \mathrm{CO}_{2} \mathrm{H}^{+}+\mathrm{H}, & \mathrm{R21}, \\
\mathrm{CO}_{2} \mathrm{H}^{+}+e \rightarrow \mathrm{H}+\mathrm{CO}, & \text { R22. }
\end{array}
$$

The density of $\mathrm{H}_{2}$ at the exobase is $1.3 \times 10^{5} \mathrm{~cm}^{-3}$, larger than that of $\mathbf{H}$ by a factor of about 4 . However, the effusion velocity of $\mathrm{H}_{2}$ is so much lower than that of $H$ that twice the escape flux of $\mathrm{H}_{2}$ is only $24 \%$ the escape flux of $\mathrm{H} .2 \phi_{\mathrm{H}_{2}}$ is $2.1 \times 10^{7}$ $\mathrm{cm}^{-2} \mathrm{sec}^{-1}$ while $\phi_{\mathrm{H}} \times 8.7 \times 10^{7} \mathrm{~cm}^{-2} \mathrm{sec}^{-1}$ and the total hydrogen flux is $1.1 \times 10^{8}$ $\mathrm{cm}^{-2} \mathrm{sec}^{-1}$. Near $100 \mathrm{~km}$ the mixing ratio of $\mathrm{H}_{2}$ in this scheme is $16 \mathrm{ppm}$. To account for the $L_{a}$ airglow observed by Mariners 6, 7, and 9, Anderson (1973) was obliged to assume a source for atomic hydrogen

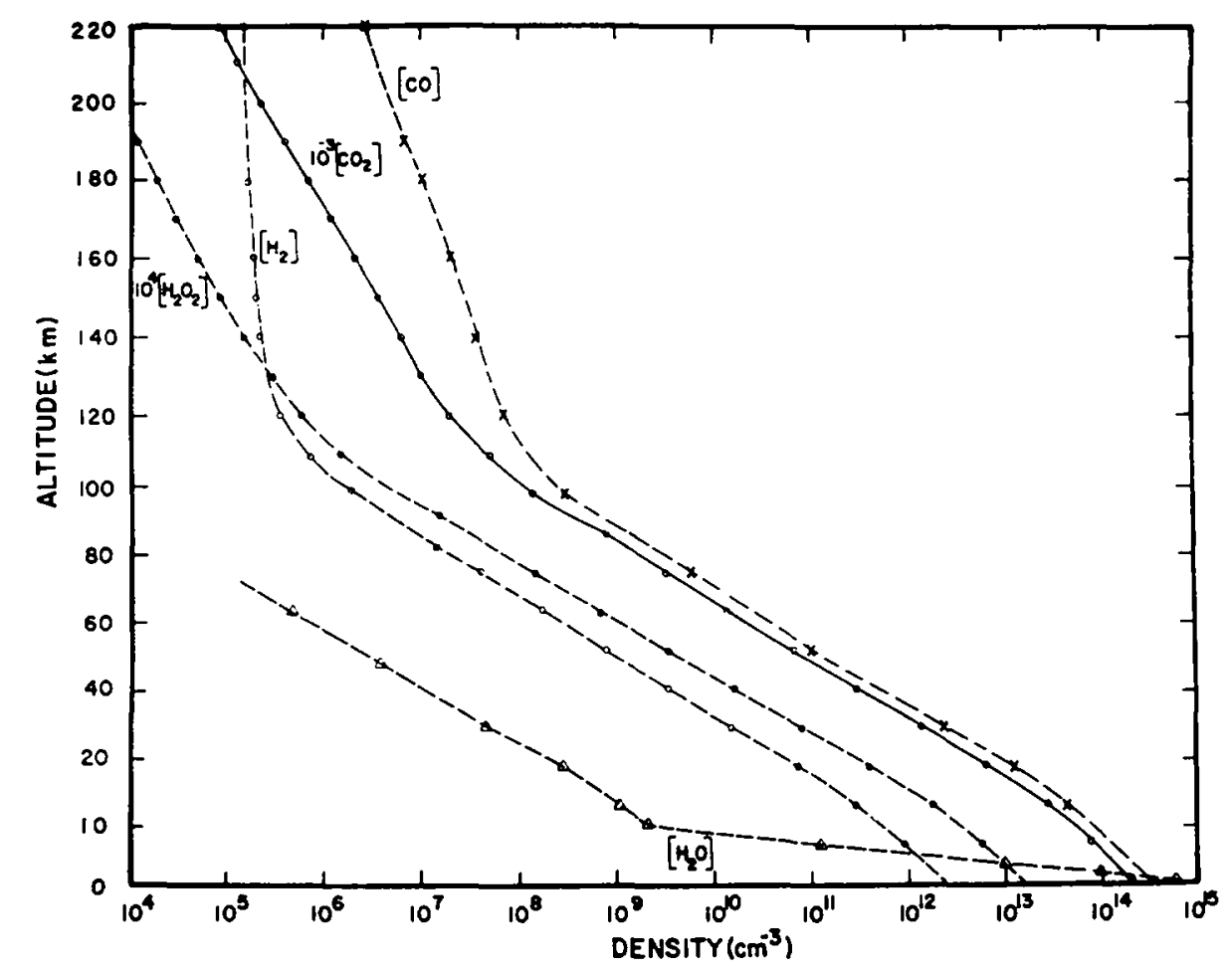

Fig. 2. Density distributions of $\mathrm{H}_{2}, \mathrm{H}_{2} \mathrm{O}, \mathrm{H}_{2} \mathrm{O}_{2}$, and $\mathrm{CO}$ for $1.3 \times 10^{-3} \mathrm{O}_{2}$ mixing ratio. Profiles corresponding to $2.6 \times 10^{-3} \mathrm{O}_{2}$ mixing ratio can be obtained by shifting thesecurveslinearly according to the ratio listed in Table II. 
which required $20 \mathrm{ppm}$ of $\mathrm{H}_{2}$ in the mesosphere and lower thermosphere. Thus, support is lent to this model by the $L_{\alpha}$ observations.

In Figs. 1 and 2 we show the densities of important species between the surface and $226 \mathrm{~km}$ under two assumptions concerning the values of the $\mathrm{O}_{2}$ mixing ratio: $1.3 \times 10^{-3}$ and $2.6 \times 10^{-3}$. In the "normal" case the surface volume mixing ratios are $[\mathrm{CO}]_{0}=1.55 \times 10^{-3}, \quad\left[\mathrm{O}_{2}\right]_{0}=1.3 \times 10^{-3}$, $\left[\mathrm{H}_{2} \mathrm{O}_{2}\right]_{0}=7 \times 10^{-9},\left[\mathrm{H}_{2}\right]_{0}=11 \times 10^{-6}$ and $\int\left[\mathrm{H}_{2} \mathrm{O}\right] d z=5 \times 10^{19} \mathrm{~cm}^{-2}(15 \mu \mathrm{m}$ of precipitable water). The abundance of ozone is $5.8 \times 10^{15} \mathrm{~cm}^{-2}$ or $2.15 \mu \mathrm{m}$-atm. The distribution of odd hydrogen and odd oxygen very closely follows that shown by McElroy and Donahue (1972, Fig. 1). In the ionosphere it is necessary to assume euv fluxes 2.7 times as large as the Hinteregger (1970) values to obtain electron and ion densities that agree with Mariner observations.

The fluxes of hydrogen and oxygen species in the "normal" case are plotted in
Figs. 3 and 4. There are several interesting features to notice in these flux curves. The escape flux of $O$ is supplied below the exobase by an upward flow of $\mathrm{CO}_{2}$ since $\mathrm{CO}_{2}$ is the species that is ionized in the exosphere. The return flux of $\mathrm{CO}$ from the exosphere is exactly the $\mathrm{CO}_{2}$ at the exobase. The downward flux of atomic oxygen at the exobase is only half the return flux of $\mathrm{CO}$ because half the oxygen resulting from dissociative recombination of $\mathrm{CO}_{2}{ }^{+}$ and $\mathrm{O}_{2}{ }^{+}$escapes while none of the $\mathrm{CO}$ does. Oxygen and $\mathrm{CO}$ flow downward, after being produced by dissociative recombination in the ionosphere. The rate of flow is enhanced below $90 \mathrm{~km}$ because of $\mathrm{CO}_{2}$ photolysis. Near $30 \mathrm{~km}$ both begin to be destroyed through reactions $R 2, \mathrm{R} 10$, and R16. Molecular oxygen is made just above $30 \mathrm{~km}$ by reaction $\mathrm{R} 2$ and dissociated in the Harzberg continuum below $15 \mathrm{~km}$ and by $\mathrm{HO}_{2}$ association. $\mathrm{H}_{2} \mathrm{O}$ is produced near $33 \mathrm{~km}$ as a result of the reaction of the odd hydrogen radicals $\mathrm{OH}$ and $\mathrm{HO}_{2}(\mathrm{R} 7)$. It is

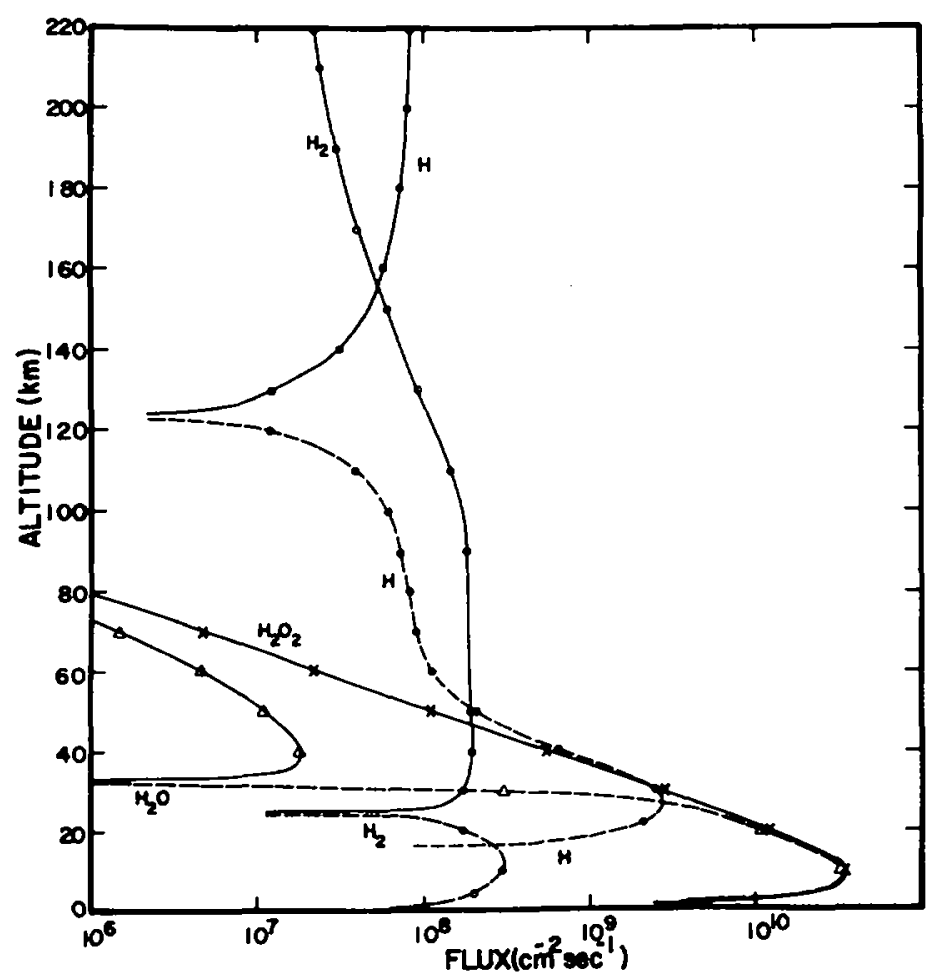

Fic. 3. Fluxes of odd hydrogen (indicated by $\mathrm{H}$ ) $\mathrm{H}_{2}, \mathrm{H}_{2} \mathrm{O}$, and $\mathrm{H}_{2} \mathrm{O}_{2}$ for $1.3 \times 10^{-3} \mathrm{O}_{2}$ mixing ratio. Solid lines indicate upward fluxes and dashed lines indicate downward fluxes. 


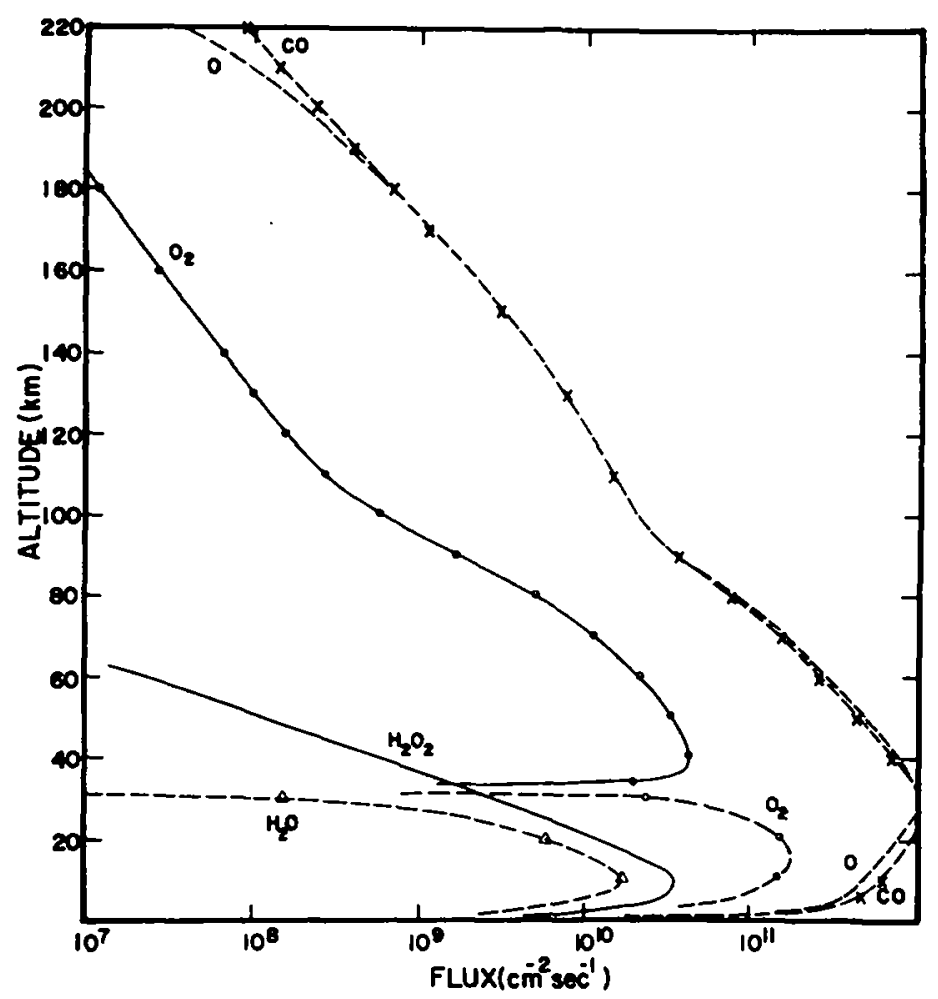

Fig. 4. Fluxes of odd oxygen (indicated by $\mathrm{O}$ ) $\mathrm{CO}, \mathrm{O}_{2}, \mathrm{H}_{2} \mathrm{O}_{2}$, and $\mathrm{H}_{2} \mathrm{O}$ corresponding to the same condition of Fig. 3. Solid lines and dashed lines indicate upward and downward fluxes, respectively.

photolyzed above $40 \mathrm{~km}$ and dissociated by $\mathrm{O}\left({ }^{1} \mathrm{D}\right)$ (produced from $\left.\mathrm{O}_{3}\right)$ below $8 \mathrm{~km}$, where it is by far the dominant source of odd hydrogen. It is interesting that the downward flux of $\mathrm{H}_{2} \mathrm{O}$ below about $25 \mathrm{~km}$ and the upward flux of $\mathrm{H}_{2} \mathrm{O}_{2}$ formed by reacting pairs of $\mathrm{HO}_{2}$ are almost numerically equal. The flux, $-\phi\left(\mathrm{H}_{2} \mathrm{O}\right)$, is about $1.7 \times 10^{10} \mathrm{~cm}^{-2} \mathrm{sec}^{-1}$ at $10 \mathrm{~km}$ while $\phi\left(\mathrm{H}_{2} \mathrm{O}_{2}\right)$ is $1.74 \times 10^{10} \mathrm{~cm}^{-2} \mathrm{sec}^{-1} . \mathrm{H}_{2}$ is clearly produced at about $25 \mathrm{~km}$ by the reaction of $\mathrm{H}$ and $\mathrm{HO}_{2}$ (R5). It flows downward to be dissociated by $\mathrm{O}\left({ }^{1} \mathrm{D}\right)$ below $12 \mathrm{~km}$, thereby recycling odd hydrogen in the chemosphere. But the upward flux begins to run into $\mathrm{CO}_{2}^{+}$in significantly large amounts near $100 \mathrm{~km}$. The reactions R21 and R22 make hydrogen atoms near $123 \mathrm{~km}$. Some of these atoms flow upward in ever increasing numbers until at the exobase they supply an escape flux of $8.7 \times 10^{7} \mathrm{H}$ atoms $\mathrm{cm}^{-2} \mathrm{sec}^{-1}$. However, there is a very sizable supply of $\mathrm{H}_{2}$ still remaining at the exobase and it supports an escape flux of $\mathrm{H}_{2}$ that amounts to $2.1 \times 10^{7}$ atoms $\mathrm{cm}^{-2} \mathrm{sec}^{-1}$. The sum is very close to twice the oxygen escape flux of $1.07 \times 10^{8} \mathrm{~cm}^{-2} \mathrm{sec}^{-1}$.

It is necessary to use a large value for the eddy diffusion coefficient in the upper atmosphere as well as in the lower atmosphere to make this scheme work: $4 \times 10^{8}$ $\mathrm{cm}^{2} \mathrm{sec}^{-1}$ in fact. Not only is this strong mixing required to bring oxygen atoms down to $30 \mathrm{~km}$ rapidly enough to reach the region where they can form $\mathrm{HO}_{2}$ in a threebody reaction before they form $\mathrm{O}_{2}$ in forbiddingly large quantities, but large values of $K$ are also needed to transport downward rapidly enough the $\mathrm{H}$ formed from the reaction of $\mathrm{H}_{2}$ and $\mathrm{CO}_{2}^{+}$and prevent [H] at the exobase from growing greater than the value $3 \times 10^{4} \mathrm{~cm}^{-3}$.

It is very important to notice that because of the relatively low density of $\mathrm{CO}_{2}{ }^{+}$, such a large fraction of $\mathrm{H}_{2}$ remains undis- 
sociated at the exobase that the limiting flux condition of Hunten (1973) is not achieved. The exospheric temperature is so low that, because of the large fraction of hydrogen in the form of $\mathrm{H}_{2}$ at high altitudes, the bottleneck for escape is at exobase. There is a large upward flux of $\mathrm{H}_{2}$ to the ionosphere and a large downward flow of $\mathrm{H}$ to form $\mathrm{H}_{2}$ and $\mathrm{HO}_{2}$ in the lower atmosphere. The escape flux is thus not controlled by the supply of hydrogen in the stratosphere and the mechanism involving control of $\mathrm{H}$ (and $\mathrm{H}_{2}$ ) escape by the nonthermal atomic oxygen escape rate can operate.

The value of the rate constant R5a for $\mathrm{H}_{2}$ production in the $\mathrm{H}, \mathrm{HO}_{2}$ reaction is $3 \times 10^{-11} \exp (-330 / T) \mathrm{cm}^{3} \mathrm{sec}^{-1}$. This is the value favored in the CIAP tables (Garvin and Hampson, 1974). It is also very important in selecting between this recombination scheme and that of Parkinson and Hunten (1972). This latter scheme is essentially a photochemical one in which the $\mathrm{O}_{2}$ bond is broken after a step of peroxide formation and photolysis added to reactions (1) and (3)

$$
\begin{gathered}
\mathrm{HO}_{2}+\mathrm{HO}_{2} \rightarrow \mathrm{H}_{2} \mathrm{O}_{2}+\mathrm{O}_{2}, \\
\mathrm{H}_{2} \mathrm{O}_{2}+h \nu \rightarrow 2(\mathrm{OH}),
\end{gathered}
$$

amounting to

$$
2 \mathrm{CO}+\mathrm{O}_{2} \rightarrow 2 \mathrm{CO}_{2} \text {. }
$$

The supply of odd hydrogen needs to be much higher in this model than in that of McElroy and Donahue (1972). Unless the rate constant $k_{5}(\mathrm{a})$ is no larger than about $3 \times 10^{-12} \mathrm{~cm}^{3} \mathrm{sec}^{-1}$, there is more $\mathrm{H}_{2}$ formed than may be destroyed by $\mathrm{O}\left({ }^{1} \mathrm{D}\right)$ and the ion molecule reactions (11) and (12).

III. Relationship among $\mathrm{O}_{2}$ Abundance, $O$ and $H$ Escape Rates

We have also performed the exercise of allowing the $\mathrm{O}_{2}$ mixing ratio to increase from $1.3 \times 10^{-3}$ in stages to $2.6 \times 10^{-3}$. In performing this exercise we keep the $\mathrm{CO}_{2}$ and $\mathrm{H}_{2} \mathrm{O}$ content of the atmosphere fixed, as well as the eddy diffusion coefficient. Thus the integrated rates of $\mathrm{CO}$ and $\mathrm{O}$ production and recombination along with $\mathrm{H}_{2} \mathrm{O}$ dissociation and reformation rates must remain unchanged. We find that if we arbitrarily increase the $\mathrm{O}_{2}$ content of the atmosphere to a new value the $\mathrm{H}$ density and $\mathrm{H}_{2}$ density at the exobase decrease. The factor by which the escape fluxes decrease is, however, always greater than the factor by which the $\mathrm{O}_{2}$ content of the atmosphere is assumed to increase. Thus if we change the mixing ratio of $\mathrm{O}_{2}$ from $1.3 \times 10^{-3}$ to $2.6 \times 10^{-3}$, the $\mathrm{H}$ density at the exobase goes from $3.1 \times 10^{4}$ to $1.1 \times 10^{4} \mathrm{~cm}^{-3}$, and the $\mathrm{H}_{2}$ density from $1.4 \times 10^{5}$ to $5.0 \times 10^{4} \mathrm{~cm}^{-3}$ (Note that $\mathrm{H}_{2}$ and $\mathrm{H}$ decrease by the same factor.) The escape fluxes go to the values

$$
\phi(\mathrm{H})+2 \phi\left(\mathrm{H}_{2}\right)=3 \times 10^{7}+7.7 \times 10^{6}
$$

or $3.8 \times 10^{7} \mathrm{~cm}^{-2} \mathrm{sec}^{-1}$ in place of $1.1 \times 10^{8}$ $\mathrm{cm}^{-2} \mathrm{sec}^{-1}$.

In Fig. 5 we show the hydrogen fluxes for the case of doubled $\mathrm{O}_{2}$ abundance. The chain that begins with an increase in $\mathrm{O}_{2}$ mixing ratio and ends in a decrease in the hydrogen density at the exobase is the following. The ozone abundance grows along with the $\mathrm{O}_{2}$ abundance because of reaction $R 20$. The result is a doubling in $\left[\mathrm{O}_{3}\right]$ and a doubling of the rate of production of $\mathrm{O}\left({ }^{1} \mathrm{D}\right)$. The lifetime of $\mathrm{H}_{2}$ against destruction by $O\left({ }^{1} \mathrm{D}\right)$ thus is cut in two. Meanwhile the reaction of $\mathrm{H}$ with $\mathrm{O}_{2}$ (R17) causes $[\mathrm{H}]$ to decrease and $[\mathrm{HO}]_{2}$ together with $[\mathrm{OH}]$ to increase. The effect is to cause a decrease in total $\mathrm{H}_{2}$ production in the reaction between $\mathrm{H}$ and $\mathrm{HO}_{2}$ (R5). The combined effect of enhanced destruction and diminished production causes the overall decrease in the $\mathrm{H}_{2}$ density, and consequently the decrease in both $\mathrm{H}_{2}$ and $\mathrm{H}$ density at the exobase, since $\mathrm{H}$ is derived from $\mathrm{H}_{2}$ in the upper atmosphere via the ionosphere reactions $\mathrm{R} 21$ and $\mathrm{R} 22$.

An increase in the $\mathrm{O}_{2}$ mixing ratio by $50 \%$ to $1.95 \times 10^{-3}$ provokes a decrease in $\mathrm{H}$ and $\mathrm{H}_{2}$ densities at the exobase by a factor of 1.8 with a corresponding decrease in escape flux. It will be noted that in Figs. 1 and 2 there are only small changes in most atmospheric constituents apart from $\mathrm{H}, \mathrm{H}_{2}$, and $\mathrm{CO}$ in response to these large changes in $\mathrm{O}_{2}$. These changes are 


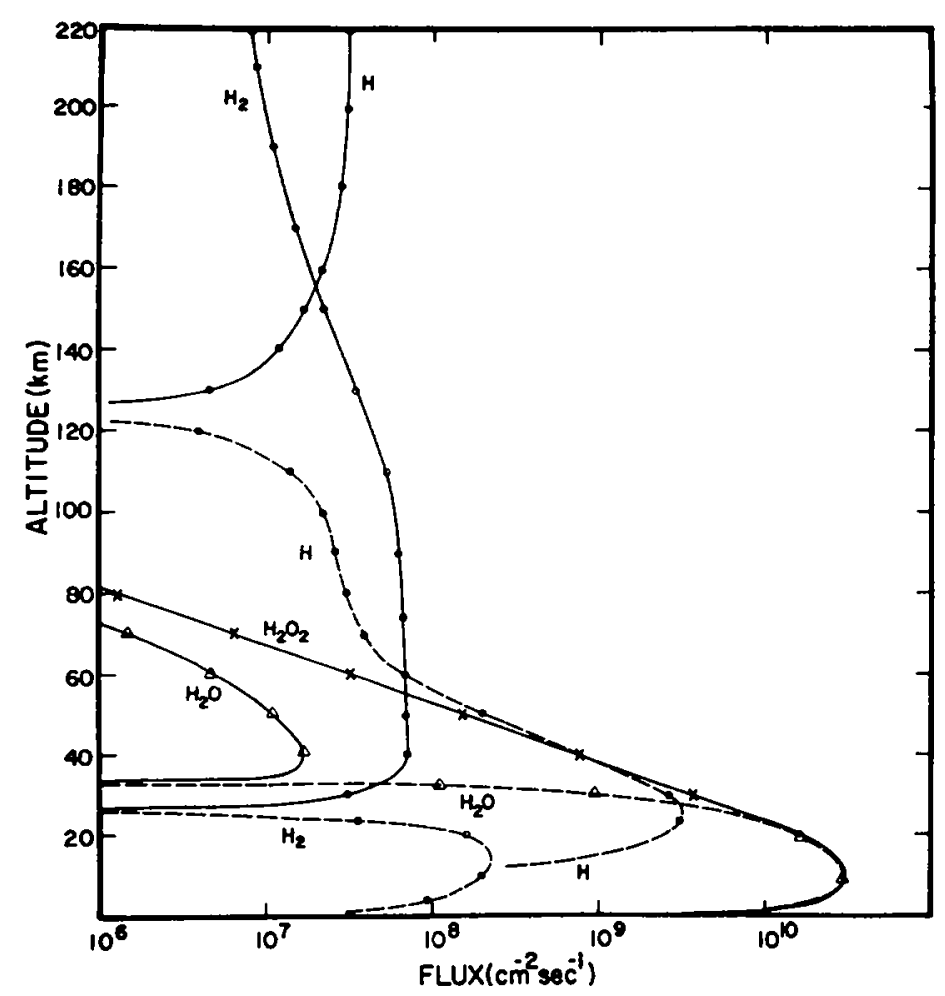

FIG. 5. Fluxes of odd hydrogen (indicated by $\mathrm{H}$ ) $\mathrm{H}_{2}, \mathrm{H}_{2} \mathrm{O}$, and $\mathrm{H}_{2} \mathrm{O}_{2}$ for $2.6 \times 10^{-3} \mathrm{O}_{2}$ mixing ratio. Solid lines indicate upward fluxes and dashed lines indicate downward fluxes.

TABLE II

Regponse of Atmospheric Constituents to Changes in $\mathrm{O}_{2}$ Mixing Ratio

\begin{tabular}{llll}
\hline $\left.\mathrm{O}_{2}\right]_{0}$ & $1.3 \times 10^{-3}\left[\mathrm{CO}_{2}\right]$ & $1.95 \times 10^{-3}\left[\mathrm{CO}_{2}\right]$ & $2.6 \times 10^{-3}\left[\mathrm{CO}_{2}\right]$ \\
{$[\mathrm{CO}]_{0}$} & $1.6 \times 10^{-3}\left[\mathrm{CO}_{2}\right]$ & $1.27 \times 10^{-3}\left[\mathrm{CO}_{2}\right]$ & $1.03 \times 10^{-3}\left[\mathrm{CO}_{2}\right]$ \\
{$\left[\mathrm{H}_{2}\right]_{0}$} & $1.1 \times 10^{-3}\left[\mathrm{CO}_{2}\right]$ & $6.1 \times 10^{-6}\left[\mathrm{CO}_{2}\right]$ & $3.9 \times 10^{-6}\left[\mathrm{CO}_{2}\right]$ \\
{$\left[\mathrm{H}_{2}\right]_{226}$} & $1.4 \times 10^{5} \mathrm{~cm}^{-3}$ & $7.8 \times 10^{4} \mathrm{~cm}^{-3}$ & $5.0 \times 10^{4}$ \\
{$[\mathrm{H}]_{226}$} & $3.1 \times 10^{4} \mathrm{~cm}^{-3}$ & $1.77 \times 10^{4}$ & $1.1 \times 10^{4}$ \\
\hline
\end{tabular}

summarized in Table II. Naturally the $\mathrm{CO}$ mixing ratio must decrease as the $\mathrm{O}_{2}$ mixing ratio increases, because there are relatively more $\mathrm{HO}_{2}$ and $\mathrm{OH}$ than $\mathrm{H}$ atoms due to reaction ( $\mathrm{R} 17$ ), and the $\mathrm{CO}$ mixing ratio must decrease to keep $\left(I_{2}\right)$ constant.

Now it must be realized that we have not performed a time-dependent calculation in which the $O$ escape flux was caused to vary by some mechanism-change in exobase level, or change in euv flux, for example-and the development of the $\mathrm{O}_{2}$ mixing ratio tracked along with the hydrogen escape flux as the oxygen flux varied. This would demonstrate that twice the hydrogen escape rate accurately follows the oxygen escape rate if the change is slow, or tends to that rate following a sudden change. To do so would require more computer facilities than we have. Furthermore, it is not necessary, for we have shown that changing the $\mathrm{O}_{2}$ mixing ratio has a profound effect on the $H$ escape flux, since the escape flux changes by a larger factor than the change of the total $\mathrm{O}_{2}$ content of the atmosphere. Therefore, 
it may be argued that if in reality the nonthermal atomic oxygen escape rate were to change, whether slowly or suddenly, the effect would be necessarily to cause the $\mathrm{O}_{2}$ content of the atmosphere to change in the opposite sense, and this, as we have seen, would provoke a change in the hydrogen escape flux in the same sense as the change in the $O$ flux. Furthermore, small changes in $\mathrm{O}_{2}$ provoke large changes in $\mathrm{H}_{2}$ concentration, and consequently in $\mathrm{H}$ production, because of the role played by $\mathrm{HO}_{2}$. It follows necessarily, therefore, that the hydrogen escape flux will change in response to the change in oxygen flux. As soon as that flux reaches a new steadystate value, the atmosphere will settle down to a new steady state in which half the hydrogen flux is equal to the oxygen flux and the $\mathrm{O}_{2}$ content of the atmosphere has a new equilibrium value. Of course we can conclude from the exercise we have conducted that the $\mathrm{O}_{2}$ reduction provoked by a factor of 2 increase in the $O$ escape rate will be by less than a factor of 2 . There is however, no possibility that an increase, say, in the oxygen escape rate, will cause a runaway in which the decrease in $\mathrm{O}_{2}$ in the atmosphere provokes a larger response in hydrogen flux than the oxygen escape flux that caused the $\mathrm{O}_{2}$ to decrease. The reason is that an overshoot in the hydrogen escape will cause the $\mathrm{O}_{2}$ in the atmosphere to begin to build up again and to cause the $\mathrm{H}$ escape rate to diminish. Thus the system is a stable one.

\section{IV. $\mathrm{O}_{3}, \mathrm{H}_{2} \mathrm{O}$, and the Polar Cap}

It is important to investigate the condition of the atmosphere above the winter and spring polar cap. It has been observed that the water vapor content of the atmosphere drops below the minimum detectable value of $10 \mu \mathrm{m}$ (less than $0.5 \mu \mathrm{m}$ according to results reported from Mars 3), while ozone is observed to rise to as much as 10 to $15 \mu \mathrm{m}$-atm just after sunrise over the polar cap. We would expect a decrease in water vapor to provoke a reduction in odd hydrogen in the lower atmosphere and thus to cause an increase in the $\mathrm{O}_{3}$ abundance. To test the quantitative nature of this effect, we have let the water vapor content of the atmosphere decrease in steps from $15 \mu \mathrm{m}$ to $7.5,3.7,0.3$ down to $3 \times 10^{-3} \mu \mathrm{m}$. The atmosphere is otherwise assumed to be identical with the standard one we developed at lower latitudes, i.e., to have the same eddy coefficient profile,

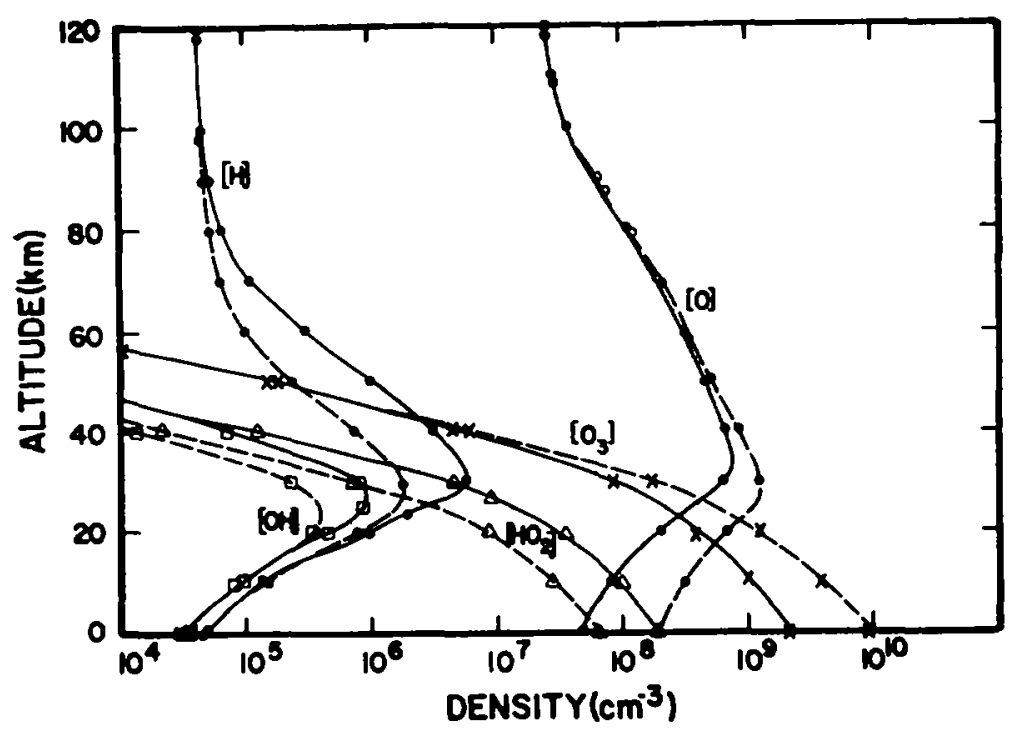

FıG. 6. Density distributions of $\mathrm{H}, \mathrm{OH}, \mathrm{HO}_{2}, \mathrm{O}$, and $\mathrm{O}_{3}$ for winter polar region. Solid lines correspond to $15 \mu \mathrm{m}$ of $\mathrm{H}_{2} \mathrm{O}$ and dashed lines correspond to $0.3 \mu \mathrm{m}$ of $\mathrm{H}_{2} \mathrm{O}$. 
TABLE III

$\mathrm{H}_{2} \mathrm{O}$ Compared to $\mathrm{O}_{3}$ Concentration over the Spring Polar CaP

\begin{tabular}{cc}
\hline $\begin{array}{c}\mathrm{H}_{2} \mathrm{O} \\
(\mu \mathrm{m})\end{array}$ & $\begin{array}{c}\mathrm{O}_{3} \\
(\mu \mathrm{m} \cdot \mathrm{atm})\end{array}$ \\
\hline 15 & $\cdots .92$ \\
7.5 & 1.4 \\
3.7 & 2.0 \\
0.3 & 3.9 \\
$3 \times 10^{-3}$ & 5.2
\end{tabular}

and, in the case of all long-lived species, the same mixing ratios globally. The profiles of odd hydrogen and odd oxygen for the cases of 15 and $0.3 \mu \mathrm{m}$ of $\mathrm{H}_{2} \mathrm{O}$ are plotted in Fig. 6. We have assumed the solar zenith angle to be $80^{\circ}$. Such large slant paths reduce the photolyzing and ionizing fluxes for optically thick media such as $\mathrm{CO}_{2}$, but have little effect on $\mathrm{O}_{3}$, since the ozone is optically thin. The results are shown in Table III. The increase in ozone predicted is about one-half as great as that observed even after a reduction by $1 / 5000$ in the amount of water vapor. It must be recognized, however, that the results in the table are for a steady state with a sun $10^{\circ}$ above the horizon. What is really observed during the early spring on Mars is no doubt a decay of the large quantity of ozone built up during the long polar night.

\section{Surface Sink}

In our "normal" atmosphere the $2 \mu \mathrm{m}$ atm of ozone predicted is just at the limit of detectability. It should be remarked in this connection, however, that our lower boundary condition of zero flux into the surface is obviously far from realistic in the case of reactive species such as $\mathrm{O}_{3}, \mathrm{O}$, and the odd hydrogen radicals. If in fact we make the extreme assumption that every ozone molecule striking the surface is lost, the flux into the surface is given by

$$
\phi\left(\mathrm{O}_{3}\right)=-\left(\left[\mathrm{O}_{3}\right] / 4\right)\left[8 k T / \pi m\left(\mathrm{O}_{3}\right)\right]^{1 / 2} \text {. }
$$

When the distribution of $\mathrm{O}_{3}$ is that shown in Fig. 1, the flux will be $3.6 \times 10^{13} \mathrm{~cm}^{-2}$ sec $^{-1}$. The total ozone content of the atmosphere $(2.04 \mu \mathrm{m}-\mathrm{atm})$ is $5.5 \times 10^{15} \mathrm{~cm}^{-2}$ and this flux gives the ozone a lifetime of only a little over $2 \mathrm{~min}$. Assuming that every $\mathrm{O}_{3}$ and every $\mathrm{O}$ striking the surface is lost, we have calculated a downward flow of $\mathrm{O}$ and $\mathrm{O}_{3}$, that would change the distributions of $\mathrm{O}$ and $\mathrm{O}_{3}$ in the way shown in Fig. 7 in order to supply the flow into the surface. The result would be to reduce the $\mathrm{O}_{3}$ content of the atmosphere from $5.5 \times 10^{15}$ to $1.9 \times 10^{15} \mathrm{~cm}^{-2}$, or from 2 to $0.7 \mu \mathrm{m}$-atm. However, the $\mathrm{O}\left({ }^{1} \mathrm{D}\right)$ production, thence the odd hydrogen production, the supply of $\mathrm{O}$ to form $\mathrm{OH}$ from $\mathrm{HO}_{2}$, are all changed in the $20 \mathrm{~km}$ layer above the surface when these effects are accounted for. On the other hand there will probably be enhanced recombination of $\mathrm{CO}$ and $\mathrm{O}$ on surface dust grains or aerosols also. Thus it is very likely that surface chemistry as well as gas-phase chemistry plays a very important role in the stability problem, as others (McElroy and Hunten, 1970; Whitten and Sims, 1973) have also pointed out. Note, however, that unless there is an important outgassing of $\mathrm{O}_{2}$ from the surface, the $\mathrm{O}_{2}$ production is not seriously enhanced, since the densities are little affected in the region above $20 \mathrm{~km}$ where most of the $\mathrm{O}_{2}$ is produced by reaction between $\mathrm{O}$ and $\mathrm{OH}$.

To gauge the severity of the problem caused by loss of reactive species upon collision with the Martian surface, we have assumed as an extreme case that the odd hydrogen constituents $\mathrm{H}, \mathrm{OH}$, and $\mathrm{HO}_{2}$ and the odd oxygen components $\mathrm{O}$ and $\mathrm{O}_{3}$ are lost as such upon every collision with the surface. Then we have calculated the distribution that will result, taking into account the loss of $O\left({ }^{1} \mathrm{D}\right)$ production that results from the loss of $\mathrm{O}_{3}$ near the surface and the consequent reduced production of odd hydrogen. The result are shown in Fig. 7. Two models were tried under the latter assumption. In one, the eddy diffusivity $K$ was assumed to remain at $4 \times 10^{8}$ $\mathrm{cm}^{2} \mathrm{sec}^{-1}$ all the way to the surface. In the other model, $K$ was allowed to decrease from 4 to $0.7 \times 10^{8} \mathrm{~cm}^{2} \mathrm{sec}^{-1}$ in the last $10 \mathrm{~km}$, following Gierash and Goody (1968). The latter assumption is essential. When $K$ 


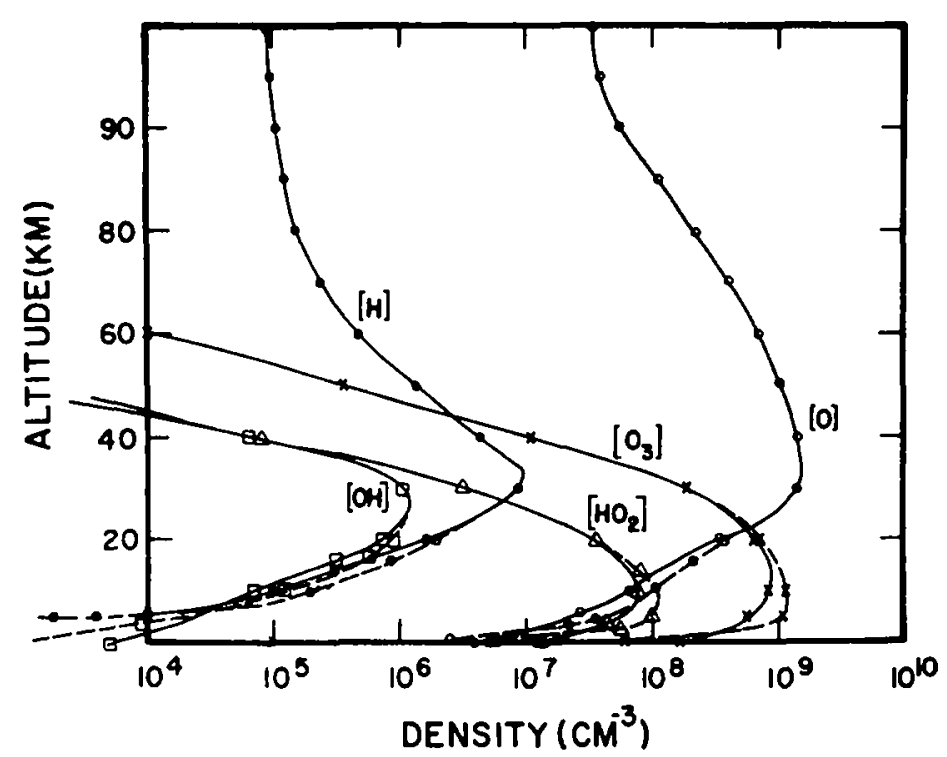

Fia. 7. Density distributions of $\mathrm{H}, \mathrm{OH}, \mathrm{HO}_{2}, \mathrm{O}$, and $\mathrm{O}_{3}$ for assumed surface reactions. Solid lines correspond to constant eddy diffusivity $K=4 \times 10^{8} \mathrm{~cm}^{2} \mathrm{sec}^{-1}$ and dashed lines correspond to $K$ decreasing from 4 to $0.7 \times 10^{8} \mathrm{~cm}^{2} \mathrm{sec}^{-1}$ in the $10 \mathrm{~km}$ above the surface (Gierash and Goody, 1968).

remains large at all altitudes, the flux of odd oxygen into the surface is $1.1 \times 10^{12}$ $\mathrm{cm}^{-2} \mathrm{sec}^{-1}$ out of a total production of $3.6 \times 10^{12} \mathrm{~cm}^{-2} \mathrm{sec}^{-1}$. The flux of odd $\mathrm{H}$ is $1.3 \times 10^{11} \mathrm{~cm}^{-2} \mathrm{sec}^{-1}$, while the total production is only $1.9 \times 10^{11} \mathrm{~cm}^{-2} \mathrm{sec}^{-1}$. On the other hand, the surface fluxes of odd oxygen and odd hydrogen drop to $4 \times 10^{11}$ and $4.5 \times 10^{10} \mathrm{~cm}^{-2} \mathrm{sec}^{-1}$ in the second model.

We have not tried to develop a completely self-consistent model with surface losses accounted for, although there is no problem in doing so mechanically. The problem is that we do not know how to estimate the fraction of $\mathrm{H}, \mathrm{OH}$, and $\mathrm{HO}_{2}$ emerging from the surface as $\mathrm{H}_{2}$ and $\mathrm{H}_{2} \mathrm{O}$; ; the fraction of $\mathrm{O}$ and $\mathrm{O}_{3}$ emerging as $\mathrm{O}$; and the fraction of $\mathrm{CO}$ that recombines to $\mathrm{CO}_{2}$ on the surface. If we leave the mixing ratio of $\mathrm{CO}$ at $1.6 \times 10^{-3}$, then the amount recombined is only $1.8 \times 10^{12}$ out of $3.3 \times 10^{12} \mathrm{~cm}^{-2} \mathrm{sec}^{-1}$ produced, because of the decrease in $\mathrm{OH}$ density (i.e., the loss of $\mathrm{OH}$ to the surface). It would be necessary only to increase the mixing ratio of $\mathrm{CO}$ to about $2.9 \times 10^{-3}$ in order to reestablish a steady state, if we assume no surface re- combination of $\mathrm{CO}$. This value is still within the limits set by Young (1971), though not if that value is revised to accommodate the data of Tubb and Williams (1972). [The data of Carleton and Traub (1972) indicate a range from 9 to $11 \times 10^{-4}$ for the volume mixing ratio.] In our opinion, uncertainty with regard to aerosol and surface removal of $\mathrm{CO}$ and the other species involved in the chemistry within $10 \mathrm{~km}$ of the surface do not allow much significance to be attached to the disparity between the calculated and measured $\mathrm{CO}$ mixing ratios under these circumstances.

The ozone abundances are 0.64 and $0.86 \mu \mathrm{m}-\mathrm{atm}$ in the two models considered here. Loss of $\mathrm{O}_{3}$ to the surface puts the total amount in the atmosphere far below the Mariner 9 limit for the "wet" atmosphere.

\section{Vi. Argon in the Atmosphere}

There has always been some uncertainty regarding the amount of argon that might exist in the Martian atmosphere. The radio occultation results which are composition 
dependent are not inconsistent with an argon abundance of 0.20 by volume. Recently, the instruments aboard Mars 6 inferred a gas that could not be exhausted from the mass spectrometer ion pump. This indirect measurement has been interpreted as indicating the presence of several tens of percent of an inert gas, such as argon. This argon inference is consistent with the radiogenic argon model of Levine and Riegler (1974), which predicts about $5 \mathrm{~g} \mathrm{~cm}^{-2}$ of argon corresponding to about $28 \%$ of argon by volume $(1.8 \mathrm{mbar}$ partial pressure of argon). It appears to be possible that at $6.8 \mathrm{mb}$ pressure level on Mars, the atmosphere may consist of $70 \% \mathrm{CO}_{2}$ and $30 \% \mathrm{Ar}$. We have assumed the existence of such an atmosphere and repeated our calculations. One of the principal effect of the presence of argon is to increase the altitude of the exobase for atomic oxygen escape from the dissociative recombination mechanism. When the standard conditions of an $\mathrm{O}_{2}$ mixing ratio of $1.3 \times 10^{-3}$ at the surface is assumed and the amount of precipitable water is taken as $20 \mu \mathrm{m},[\mathrm{H}]_{226}$ taken to be $3.3 \times 10^{4} \mathrm{~cm}^{-3}$, the escape flux of atomic oxygen is found to be $3.5 \times 10^{7} \mathrm{~cm}^{-2} \mathrm{sec}^{-1}$. In the case of the argon-rich atmosphere, the exobase for oxygen escape increases to 246 from $226 \mathrm{~km}$. However, the ion densities are higher in the ratio of 1.21 at the same altitude because of the additional ionization of argon and subsequent charge exchange of $\mathrm{Ar}^{+}$and $\mathrm{CO}_{2}$. Thus it appears that the height of the exobase is to a certain extent offset by the increase in recombination rate.

The solution to the coupled flow equations (with no surface loss) is then found to produce an atmosphere with the following characteristics:

$$
\begin{aligned}
K & =2.5 \times 10^{8} \mathrm{~cm}^{2} \mathrm{sec}^{-1}, \\
{[\mathrm{CO}]_{0} } & =2.02 \times 10^{-3}\left[\mathrm{CO}_{2}\right]_{0}, \\
{\left[\mathrm{H}_{2}\right]_{0} } & =15.5 \mathrm{ppm}^{-} \\
{\left[\mathrm{H}_{2} \mathrm{O}_{2}\right]_{0} } & =2 \times 10^{9} \mathrm{~cm}^{-3}, \\
{\left[\mathrm{H}_{2}\right]_{226} } & =1.63 \times 10^{5} \mathrm{~cm}^{-3} \\
\phi_{\mathrm{H}} & =8.7 \times 10^{7} \mathrm{~cm}^{-2} \mathrm{sec}^{-1}, \\
2 \phi_{\mathrm{H}_{2}} & =3 \times 10^{7} \mathrm{~cm}^{-2} \mathrm{sec}^{-1} \\
\int[\mathrm{O}]_{3} d z & =5 \times 10^{15} \mathrm{~cm}^{-2} \text { or } 1.86 \mu \mathrm{m}-\mathrm{atm} .
\end{aligned}
$$

The hydrogen escape flux is $1.17 \times 10^{8}$ $\mathrm{cm}^{-2} \mathrm{sec}^{-1}$ and is not in balance with the oxygen flux. A lower value of $K$ is more tolerable than previously, because the total amount of $\mathrm{CO}_{2}$ is reduced to $4.8 \mathrm{mb}$.

If we cut the $\mathrm{O}_{2}$ mixing ratio to $0.65 \times 10^{-3}$ but leave the same water vapor, $\mathrm{CO}_{2}$ and $\mathrm{Ar}$ conditions, we find a solution with the following characteristics :

$$
\begin{aligned}
& {[\mathrm{CO}]_{0}=} 2.8 \times 10^{-3}\left[\mathrm{O}_{2}\right]_{0}, \\
& {\left[\mathrm{H}_{2}\right]_{0}=} 40 \mathrm{ppm}, \\
& {\left[\mathrm{H}_{2} \mathrm{O}_{2}\right]_{0}=} 1.5 \times 10^{9} \mathrm{~cm}^{-3}, \\
& {[\mathrm{H}]_{226}=} 8.4 \times 10^{4} \mathrm{~cm}^{-3}, \\
& {\left[\mathrm{H}_{2}\right]_{226}=} 4.2 \times 10^{5} \mathrm{~cm}^{-3} \\
& {\left[\mathrm{O}_{3}\right] d z=} 2.8 \times 10^{15} \mathrm{~cm}^{-2} \\
& \text { or } 1.04 \mu \mathrm{m}-\mathrm{atm} \\
& \phi_{\mathrm{H}}+2 \phi_{\mathrm{H}_{2}}= 2.2 \times 10^{8}+0.75 \\
& \times 10^{8} \mathrm{~cm}^{-2} \mathrm{sec}^{-1}
\end{aligned}
$$

A reduction in $\mathrm{O}_{2}$ by a factor of 2 induces an increase in hydrogen escape flux $\phi$ by a factor of 2.6, an effect almost as large as that in the argon free atmosphere where the change in hydrogen flux was by a factor of 2.9 when the $\mathrm{O}_{2}$ concentration changed by a factor of 2 .

To get the hydrogen escape flux to balance the oxygen escape flux $\left(3.5 \times 10^{7}\right.$ $\mathrm{cm}^{-3} \mathrm{sec}^{-1}$ ) the mixing ratio of $\mathrm{O}_{2}$ is required to be $1.65 \times 10^{-3}$, slightly higher than the measured value of $1.3 \times 10^{-3}$. We hesitate to cite this imbalance in hydrogen and oxygen escape flux as evidence against a large argon abundance on Mars, in view of the many uncertainties in other measured quantities-exospheric temperature, rate constants such as $k_{5}$ and $k_{7}$, hydrogen density at the exobase, and the assumption that the hydrogen and oxygen escape rates must balance at all times (that is to say, at present). But there is more than a hint here that the Martian atmosphere would be easier to understand if the ratio of $\mathrm{CO}_{2}$ to other gases such as Ar were a good deal greater than $7 / 3$.

\section{Conclusions}

Martian photochemistry that recombines $\mathrm{CO}$ and $\mathrm{O}$ to $\mathrm{CO}_{2}$ through a water catalytic cycle enables the nonthermal escape of oxygen to govern the thermal 
escape of hydrogen. The result is that water escapes from Mars, not hydrogen alone, and there is no pronounced tendency for $\mathrm{H}$ of $\mathrm{O}$ to accumulate as a result of escape.

\section{ACKNOWLEDGMENTS}

We thank G. R. Carignan, N. D. Sze, S. R. Drayson, J. S. Levine, and D. W. Rusch for useful discussions and information. The research reported here was supported by the Atmospheric Sciences Section, National Science Foundation (NSF Grant DES74-21598).

\section{Referexces}

Albers, E. A., Heyermans, K., Waqner, H. G. G., and Wolfrum, J. (1971). Absolute measurements of rate coefficients for the reactions of $\mathrm{H}$ and $\mathrm{O}$ atoms with $\mathrm{H}_{2} \mathrm{O}_{2}$ and $\mathrm{H}_{2} \mathrm{O}$. In Proceedings of the Thirteenth Symposium on Combustion, pp. 81-88. The Combustion Institute, Pittsburgh.

ANDERSon, D. E., JR. (1973). The distribution of atomic hydrogen in the thermosphere and exosphere of Mars as determined from Mariner 6, 7 and 9 ultraviolet measurements. Thesis, University of Colorado.

BARkER, E. S. (1972). Detection of molecular oxygen in the Martian atmosphere. Nature 238, 447-448.

Barker, E. S., Schorn, R. A., Woszczyk, A., Tull, R. G., ANd Litrle, S. J. (1970). Mars: Detection of atmospheric water vapor during the southern hemisphere spring and summer season. Science 170, 1308-1310.

Barth, C. A., Hord, C. W., Stewart, A. I., Lave, A. L., Dick, M. L., AND Anderson, G. P. (1973). Marine 9 ultraviolet spectrometer experiment: Seasonal variation of ozone on Mars. Science 179, 795-796.

Barth, C. A., ANd Dick, M. L. (1974). Ozone and the polar hood of Mars. Icarus 22, 205-211.

BaUer, S. J. (1973). In Physics of Planetary Ionospheres (J. G. Roederer, Ed.), p. 85. Springer, New York.

Baulch, D. L., Drygdate, D. D., and Lloyd, A. C. (1969). High Temp. Reaction Rate Data $3,18$.

Biedenkapp, D., Hartshorn, L. G., and Bair, E. J. (1970). The $\mathrm{O}\left({ }^{1} \mathrm{D}\right)+\mathrm{H}_{2} \mathrm{O}$ reaction. Chem. Phys. Lett. 5, 379.

Carleton, N. P., and Trayb, W. A. (1972). Detection of molecular oxygen on Mars. Science 177, 988.

Clark, I. D., and Noxon, J. F. (1972). Optical emission from $O\left({ }^{1} D\right)$ and $\mathrm{O}_{2}\left(b^{1} \Sigma_{q}\right)$ in ultra. violet photolysis of $\mathrm{O}_{2}$ and $\mathrm{CO}_{2}$, II. J. Chem. Phys. 57, 1033.

Clyne, M. A. A., and Throsh, B. A. (1963a). Rates of elementary processes in the chain reaction between hydrogen and oxygen. $I$. Reactions of oxygen. Atmos. Proc. Roy. Soc. $A$ 275, 544-558.

Conrath, B., Curran, R., Hayel, R., Kunde, V., Magutre, W., Peari, J., Pirraglia, J., Welker, J., ANd Burke, T. (1973). Atmospheric and surface properties of Mars obtained by infrared spectroscopy on Mariner $9 . J$. Geophys. Res. 78, 4267-4278.

Donarue, T. M. (1971). Aeronomy of $\mathrm{CO}_{2}$ atmospheres: A review. J. Atmos. Sci. 28, 895-900.

Fehsenfeld, F. C., Schmeltekopy, A. L., Denkin, D. B., and Fergeson, E. E. (1969). Compilation of reaction rate constants measured in the ESSA flowing afterflow system to August, 1969. ESSA, Tech. Report, ERL 135-AL 3 (C.S. Dept. of Commerce).

Fehsenteld, F. C., Denkin, D. B., and Ferguson, E. E. (1970). Rate constants for the reaction of $\mathrm{CO}_{2}{ }^{+}$with $\mathrm{O}, \mathrm{O}_{2}$ and $\mathrm{NO} ; \mathrm{N}_{2}{ }^{+}$with $\mathrm{O}$ and $\mathrm{NO}$; and $\mathrm{O}_{2}{ }^{+}$with NO. Planet. Space Sci. 18, 1267-1269.

Fehsenteld, F. C., and Ferguson, E. E. (1972). Thermal energy reaction rate constants for $\mathrm{H}^{+}$and $\mathrm{CO}^{+}$with $\mathrm{O}$ and NO.J. Chem. Phys. $56,3066$.

Garvin, D., and Hampson, R. F. (1974). Chemical kinetics data survey. VII. Tables of rate and photochemical data for modeling of the stratosphere prepared by Climatic Impact Assessment Program, Department of Transportation.

Gierasch, P. J., and Goody, R. M. (1968). A study of the thermal and dynamical structure of the Martian lower atmosphere. Planet. Space Sci. 16, 615-646.

Greiner, N. R. (1968). Hydroxyl radical kinetics by kinetic spectroscopy. III. Reactions with $\mathrm{H}_{2} \mathrm{O}_{2}$ in the range $300-458^{\circ} \mathrm{K}$. J. Phys. Chem. 72, 406-410.

Hampson, R. F., Braun, W., Brown, R. L., Garvis, D., Herros, J. T., Huie, R. E., Koryla, M. J., Laufer, A. H., McKinley, J. D., Okabe, K., Scheer, M. D., Tsang, W., and Stedman, D. H. (1973). Survey of photochemical and rate data for 28 reactions of interest in atmospheric chemistry. $J$. Phys. Chem. Ref. Data 2, 225-229.

Hinteregaer, H. E. (1970). The extreme ultraviolet solar spectrum and its variation during solar cycle. Ann. Geophys. 26, 547.

Hochanadex, C. J., Grormley, J. A., and Ogres, P. J. (1972). Absorption spectrum 
and reaction kinetics of the $\mathrm{HO}_{2}$ radical in the gas phase. J. Chem. Phys. 56, 4426-4432.

Hunten, D. M. (1973). The escape of light gases from planetary atmospheres. J. Atmos. Sci. 30, 1481-1494.

Hunten, D. M. (1974). Aeronomy of the lower atmosphere of Mars. Rev. Geophys. 12, 529535.

Hunten, D. M., and McElroy, M. B. (1970). Production and escape of hydrogen on Mars. J. Geophys. Res. 75, 5980-6001.

Hunten, D. M., and Strobel, D. F. (1974). Production and escape of terrestrial hydrogen. J. Atmos. Sci. 31, 305-317.

KaUfman, F. (1964). Aeronomic reactions involving hydrogen. A review of recent laboratory studies. Ann. Geophys. 20, 106-114.

KaUfman, F. (1969a). Neutral reactions involving hydrogen and other minor constituents. Can. J. Chem. 47, 1917-1926.

KaUfman, F. (1969b). Elementary gas reactions. Ann. Rev. Phys. Chem. 20, 45-80.

Levinf, J. S., ANd Rifgler, G. R. (1974). Argon in the Martian atmosphere. Geophys. Res. Lett. 1, 285-287.

Liu, S. C., and Donahue, T. M. (1974a). The aeronomy of hydrogen in the atmosphere of Earth. J. Atmos. Sci. 31, 1118-1136.

Lid, S. C., and Donahte, T. M. (1974b). Mesospheric hydrogen related to exospheric escape mechanisms. J. Atmos. Sci. 81, 1466-1470.

Liv, S. C., And Donahue, T. M. (1974c). Realistic model of hydrogen constituents in the lower atmosphere and escape flux from the upper tmosphere. J. Atm̄os. Sci. 31, 2238-2242.

LiU, S. C., and Donahue, T. M. (1975). The aero. nomy of the upper atmosphere of Venus. Icarus 24, 148-156.

McConnell, J. C. (1973). The atmosphere of Mars. In Physics and Chemistry of Upper Atmospheres (B. M. McCormac, Ed.), p. 309. D. Reidel, Dordrecht, Holland.

McElroy, M. B. (1972). Mars: An evolving atmosphere. Science 175, 443.

McElroy, M. B. (1974). Atomic and molecular processes in the Martian atmosphere, Rev. Geophys. 14, 116-141.

McElkoy, M. B., ANd Donahuf, T. M. (1972). Stability of the Martian atmosphere. Science 177, 986-988.

McElroy, M. B., and Hunten, D. M. (1970). Photochemistry of $\mathrm{CO}_{2}$ in the atmosphere of Mars. J. Geophys. Res. 75, 1188.

McFlroy, M. B., and McConneli, J. C. (1971). Dissociation of $\mathrm{CO}_{2}$ in the Martian atmosphere. J. Atmos. Sci. 28, 879.
NASA (1974). Mars Engineering Model, Viking 75 Project, prepared by the NASA Langley Research Center, Viking Project Office.

Parkinson, T. D., axd Hunten, D. M. (1972). Spectroscopy and aeronomy of $\mathrm{O}_{2}$ on Mars. J. Atmos. Sci. 29, 1380.

Phillips, L. F., ANd Schiff, H. I. (1962). Mags spectrometric studies of atomic reactions. III. Reactions of hydrogen atoms with nitrogen dioxide and with ozone. J. Chem. Phys. 37, 1233-1238.

Schofield, K. (1967). An evaluation of kinetic rate data for reactions of neutrals of atmos. pheric interest. Planet. Space Sci. 15, 643-670.

Schorn, R. A. (1971). The spectroscopic search for water on Mars: A history. In Planetary Atmospheres (C. Sagan, T. C. Owen, and H. J. Smith, Eds.), pp. 223-236.

Simoxaitis, R., AND Heicklen, J. (1972). Kinetics and mechanisms of the reaction of $\mathrm{O}\left({ }^{3} \mathrm{P}\right)$ with carbon monoxide. J. Chem. Phys. 56, 2004-2011.

Slanger, T. G., Wood, B. J., and Black, G. (1972). Kinetica of $\mathrm{O}\left({ }^{3} \mathrm{P}\right)+\mathrm{CO}+\mathrm{M}$ recombination. J. Chem. Phys. 57, 233.

Strickland, D. J., Thomas, G. E., and Sparks, P. R. (1972). Mariner 6 and 7 ultraviolet spectrometer experiment: Analysis of the OI 1304- and 1356- $\AA$ emissions. $J$. Ceophys. Res. 77, 4052-4068.

STUhL, F., AND Niki, H. (1971). Measurements of rate constants for thermolecular reactions of $\mathrm{O}\left({ }^{3} \mathrm{P}\right)$ with $\mathrm{NO}, \mathrm{O}_{2}, \mathrm{CO}, \mathrm{N}_{2}$ and $\mathrm{CO}_{2}$ useing a pulsed vacuum-uv photolysis-chemiluminescent method. J. Chem. Phys. 55, 3943-3953.

TuBB, L. D., and Williams, D. (1972). Broadening of infrared absorbtion lines at reduced temperature. II. Carbon monoxide in the atinosphere of carbon dioxide. J. Opt. Soc. Amer. 62, 423-427.

Walls, F. I., and Dunn, G. H. (1974). Measurement of total cross sections for electron recombination with $\mathrm{NO}^{+}$and $\mathrm{O}_{2}{ }^{+}$using ion storage techniques. $J$. Geophys. Res. 78, 1911 .

Whimten, R. C., And Sims, J. S. (1973). The photolytic stability of the Martian atmosphere. Planet. Space Sci. 21, 1333.

Wilson, W. E., JR. (1972). A critical review of the gas-phase reaction kinetics of the hydroxyl radical. J. Phys. Ref. Data 1, 535-572.

Young, L. D. G. (1971). Interpretation of high resolution spectra of Mars. III. Calculations of $\mathrm{CO}$ abundance and rotational temperature. J. Quant. Spectrosc. Radiat. Trans. 11, 385390 . 